Aim of the study: Deregulation of insulinlike growth factor I (IGF-I) production and decreased hepatic estrogen levels were associated with development of hepatocellular carcinoma (HCC) in hepatitis $\mathrm{C}$ virus (HCV) infected cirrhotic patients. The aim of our study was to determine serum levels of IGF-I, insulin and 17- $\beta$ estradiol (17- $\beta E$ ) in relation to other markers of liver injury in chronic hepatitis $\mathrm{C}(\mathrm{CHC})$ patients.

Material and methods: Thirty anti-viral treatment-naïve CHC patients and 10 healthy subjects were examined. HCV infection was confirmed by presence of anti-HCV and HCV-RNA in serum. Serum levels of IGF-I, insulin and of 17- $\beta$ E were evaluated using ELISA methods.

Results: Serum levels of IGF-I and 17- $\beta$ E were significantly lower in $\mathrm{CHC}$ patients than in controls while insulin levels were similar in both groups. A lower IGF-I level (but not the level of 17- $\beta E$ ) was observed in cirrhotic $\mathrm{CHC}$ patients in comparison to non-cirrhotic ones. Decreased serum level of IGF-I was associated with more advanced staging and liver steatosis, higher levels of alpha-fetoprotein (AFP) and gamma globulin levels, and higher aspartate transaminase (AST) activity in $\mathrm{CHC}$ patients. Insulin and $17-\beta$ E levels positively correlated with patient's age. A positive correlation was observed between insulin level on one hand and staging, liver steatosis and levels of gamma globulins in $\mathrm{CHC}$ patients on the other. A negative correlation between IGFI and insulin levels was noted only in HCV infected patients.

Conclusions: Decreased IGF-I levels and increased levels of insulin better than estradiol serum levels characterize staging and liver steatosis in $\mathrm{CHC}$ patients. The lower serum level of $17-\beta E$ in the $\mathrm{CHC}$ group than in control patients suggests that $\mathrm{CHC}$ patients carry higher risk of liver injury and of HCC development.

Key words: IGF-I, insulin, estradiol, hepatitis C, liver cirrhosis.

\section{Alterations of insulin-like growth factor I (IGF-I) and estradiol serum levels in chronic hepatitis $C$}

\author{
Agnieszka Adamekㄹ, Aldona Kasprzak², Agnieszka Seraszek³, Hanna Mikośs, \\ Aleksandra Bura', Iwona Mozer-Lisewska ${ }^{1}$
}

1Department of Infectious Diseases, Poznan University of Medical Sciences, Poznan, Poland

2Department of Histology and Embryology, Poznan University of Medical Sciences, Poznan, Poland

${ }^{3}$ Department of Clinical Pathomorphology, Poznan University of Medical Sciences, Poznan, Poland

4Department of Pediatric Endocrinology and Diabetes, Poznan University of Medical Sciences, Poznan, Poland

\section{Introduction}

Insulin-like growth factors (IGF-I and IGF-II) manifest a structure and biological activity similar to those of insulin and they play the function of pleiotropic hormones [1]. Insulin-like growth factor I represents a secretory protein of 7,649 Da in molecular weight, consisting of a single polypeptide chain of 70 amino acids which exerts a variable effect on cells and tissues [2]. In the postnatal period the liver provides the main source of circulating IGF-I and the protein is produced mainly under the effect of growth hormone $(\mathrm{GH})$. Secretion of IGF-I is also affected by age, gender, diet and nutrition, insulin and sex hormones. Insulin-like growth factor I produced in liver manifests mainly endocrine activity while IGF-I synthesized in other tissues acts in a para- and/or autocrine manner [2].

In chronic hepatitis C virus ( $\mathrm{HCV}$ ) infection, an imbalance between proliferation and apoptosis of hepatocytes may result in a loss of normal response to growth factors, including IGF-I and II [3]. Insulin-like growth factor I may play a role in persistence of chronic hepatitis by control of pro-inflammatory cytokine signaling pathways and endothelial receptors for adhesion factors (e.g. ICAM-1) [4], and in induction of an acute inflammatory response, triggered by tumor cells during early stages of liver metastases [5-7]. In the mouse model of obesity, IGF-I was demonstrated to represent a critical factor both in activation and persistence of hepatitis in normal and obese individuals, the factor which provides a necessary condition for development of metastases to the liver. The effect of IGF-I is both direct (paracrine) and indirect, through the effect on the hepatic microenvironment [8].

The decrease in serum levels of both IGFs with progression of liver pathology, independently of its etiology, was described in the 1970s [8-11]. Serum levels of IGF-I in chronic hepatitis C (CHC) patients decrease with increase of fibrosis score [11]. In liver cirrhosis lowered concentrations of IGF-I were noted, as compared to healthy individuals, particularly in more advanced stages of cirrhosis [10, 11], as well as an increased concentration of growth factor following administration of anti-viral therapy [11]. The studies confirmed decreased concentrations of both IGFs also in chronic HCV infection. A positive correlation with severity of the disease (Child score) was documented for both IGF-I $[12,13]$ and IGF-II [14]. Moreover, in $\mathrm{CHC}$ a reduction in serum concentration of IGF-I was found to take place approximately 9 months before development of hepatocellular carcinoma (HCC) [15]. In patients with HCC and hypoglycemia, concentration of IGF-II (but not IGF-I) was proven to be high- 
er than in patients without hypoglycemia. Elevated concentration of IGF-I was found to be accompanied by more advanced histological lesions in the liver [9]. Individual reports exist, even if based on small groups of patients $(n=12)$, according to which levels of IGF-I in patients with chronic HCV infection were higher than those in the control [16]. Studies on serum levels of IGF-I in patients with primary or metastatic hepatic tumors most frequently manifested a marked decrease in IGF-I concentration in both types of hepatic tumors, as compared to the control. The decrease was more pronounced in HCC of HCV-positive patients than in virusnegative HCC patients $[17,18]$. Mechanisms of the decrease in serum IGF-I levels in hepatic tumors continue to be discussed [17]. According to the authors of the latter report, the decreased concentration of IGF-I is supposed to reflect significant damage to liver parenchyma, but only in cases of metastatic liver carcinomas, and this does not explain the decreased IGF-I levels in most cases of primary hepatocellular carcinomas [17].

Chronic hepatitis C currently is thought to represent the most important risk factor of primary HCC. Insulin-like growth factor I stimulates hepatocyte proliferation, takes part in persistence of neoplastic phenotype in the cells, their metastases and in inhibition of their apoptosis, which has been demonstrated in hepatoma and hepatocarcinoma cell lines in humans $[3,5]$. Deregulation of IGF-I production and decreased hepatic estrogen levels were associated with the development of HCC in HCV-infected cirrhotic patients [17, 19].

The aim of our study was to determine serum levels of IGF-I, insulin and $17-\beta$ estradiol (17- $\beta \mathrm{E}$ ) in relation to other markers of liver injury in HCV-infected patients.

\section{Material and methods}

Thirty anti-viral treatment-naïve CHC patients (18 males, 12 females, mean age $47 \pm 17$ years, ranging from 19 to 84 years) were prospectively recruited from the Department of Infectious Diseases, Poznan University of Medical Sciences between January and March, 2010. Four cirrhotic patients developed HCC and died before the end of 2010. Hepatitis $\mathrm{C}$ virus infection was confirmed by presence of anti-HCV antibody (IgG) (HCV version 3.0 AXYM System, Abbott) and HCVRNA in serum (AMPLICOR HCV'M test, version 2.0, ROCHE, Mannheim, Germany with sensitivity of $600 \mathrm{IU} / \mathrm{ml}$ ). All the patients were seronegative for other viruses: HBV, HCMV, EBV, HIV-1 and HIV-2. Laboratory tests were performed according to the routinely used techniques. Serum levels of IGF-I were tested using ELISA (IEMA, IDS Ltd, Immunodiagnostic Systems Limited, Boldon, UK). Fasting levels of insulin and of $17-\beta E$ were measured with chemiluminescent immunoassays (ARCHITECT Insulin and ARCHITECT Estradiol, Abbott, Longford, Ireland). Liver biopsy was performed in each $\mathrm{CHC}$ patient. Written informed consent was obtained from each patient before liver biopsy, and approval for the study was granted by the institution's Ethical Committee.

Each tissue specimen of liver biopsy was evaluated based on a numerical scoring for the total grading of portal/periportal necroinflammation (G: $0-4)$, for the stage of fibrosis (S: 0-4) and liver steatosis (0-2), as described earlier [20]. The control group included serum samples from 10 healthy blood donors.

\section{Statistical analysis}

First, the parameters of descriptive statistics were calculated (arithmetic mean, standard deviation, median value, minimum and maximum values). Statistical analysis of qualitative traits employed the Mann-Whitney test for independent samples. Spearman's rank correlation was applied to examine the association between variable values. Differences and relationships were accepted to be statistically significant at the level of $p$ less than 0.05 . The statistical analysis was performed using Statistica PL v. 8 software.

\section{Results}

Selected clinical data of the patients with $\mathrm{CHC}$ are presented in Table 1.

Mean serum level of IGF-I was significantly lower in CHC patients than in controls $(68.1 \pm 45.42 \mathrm{ng} / \mathrm{ml}$ vs. $133.50 \pm 63.95$ $\mathrm{ng} / \mathrm{ml}$ ) (Fig. 1). A statistically significant difference in levels of 17- $\beta$ E was observed between the same groups ( $36.17 \pm 33.25$ $\mathrm{pg} / \mathrm{ml}$ and $82.20 \pm 98.89 \mathrm{pg} / \mathrm{ml}$ ) (Fig. 2). Insulin levels were similar in both groups $(29.41 \pm 38.77 \mu \mathrm{mol} / \mathrm{ml}$ vs. $22.48 \pm 14.85$ $\mu \mathrm{mol} / \mathrm{ml}$ ) (Fig. 3). A lower IGF-l level (but not of $17-\beta \mathrm{E}$ ) was observed in cirrhotic $\mathrm{CHC}$ patients in comparison to non-cirrhotic ones $(31.25 \pm 18.97 \mathrm{ng} / \mathrm{ml}$ and $82.19 \pm 44.77 \mathrm{pg} / \mathrm{ml}$, respectively) (Figs. 1 and 2). The decreased serum level of IGFI was associated with more advanced staging and liver steatosis, higher levels of AFP and gamma globulins, and higher AST activity in CHC patients (Figs. 4 and 5). In CHC patients IGF-I serum levels negatively correlated with patients' age $(r=-0.6884, p<0.05)$ (data not shown).

In chronic hepatitis $C$ patients, insulin levels positively $(r=0.6510, p<0.05)$, and 17- $\beta$ E levels negatively $(r=-0.5635$, $p<0.05)$ correlated with patients' age (data not shown). A positive correlation was observed between insulin level and staging, liver steatosis and gamma globulin levels in $\mathrm{CHC}$ patients (Fig. 6). A negative correlation between IGF-I and insulin levels was present only in HCV infected patients (Fig. 7). A negative correlation in $\mathrm{HCV}$-infected patients was also noted between IGF-I serum levels and BMI $(r=-0.376)$ (data not shown).

\section{Discussion}

The IGF-I protein is produced mostly in the liver. The circulating fraction of $|\mathrm{GF}-|$ is transported bound to $|\mathrm{GF}-|$ binding proteins (IGF-IBPS) types 1-6. The main transporter is IGF-IBP3, which modulates the bioactivity of IGF-I by limiting its access to IGF-IR [21].

Chronic liver injury influences IGF-I serum levels. The circulating levels are decreased in chronic viral hepatitis, particularly in HCV infection [18]. Undoubtedly, this study has shown a statistically significant difference in IGF-I levels in $\mathrm{CHC}$ patients and the healthy non-infected group. Previous studies demonstrated significant reduction of IGF-I levels in cirrhotic patients $[11,12,15]$. In accordance, this study has found a significant difference in IGF-I levels between cirrhotic and non-cirrhotic groups. Four cirrhotic patients with IGF-I levels less than $15 \mathrm{ng} / \mathrm{ml}$ developed HCC and died before the end of 2010. Such low levels of IGF-I predict rapid development of HCC. Wu et al. showed that an IGF-I level $<30 \mathrm{ng} / \mathrm{ml}$ indicated a poor prognosis, with $83 \%$ mortality in less than 
Table 1. Hormone levels, histological and selected clinical data of the patients with chronic hepatitis C

\begin{tabular}{|c|c|c|c|c|c|}
\hline Parameter & $n$ & Mean value & Min & Max & SD \\
\hline IGF-I (ng/ml) & 30 & 68.61 & 4.04 & 175.66 & 45.42 \\
\hline insulin $(\mu \mathrm{U} / \mathrm{ml})$ & 30 & 29.41 & 4.60 & 213.90 & 38.77 \\
\hline $17 \beta$-estradiol (pg/ml) & 30 & 36.17 & 5.00 & 132.00 & 33.25 \\
\hline steatosis* & 21 & 0.86 & 0.00 & 2.00 & 0.85 \\
\hline grading* $^{*}$ & 21 & 1.86 & 1.00 & 3.00 & 0.57 \\
\hline staging* & 29 & 2.28 & 1.00 & 4.00 & 1.25 \\
\hline BMI & 30 & 25.53 & 18.38 & 37.61 & 4.08 \\
\hline glucose & 26 & 111.69 & 76.00 & 203.00 & 32.81 \\
\hline bilirubin & 30 & 0.91 & 0.23 & 1.98 & 0.44 \\
\hline $\mathrm{ALT}(\mathrm{U} / \mathrm{I})$ & 30 & 92.46 & 17.00 & 292.00 & 63.53 \\
\hline AST (U/I) & 30 & 73.32 & 21.00 & 195.00 & 44.73 \\
\hline total protein $(\mathrm{g} / \mathrm{dl})$ & 30 & 7.19 & 6.02 & 8.80 & 0.66 \\
\hline albumin (g/dl) & 28 & 3.66 & 2.05 & 4.54 & 0.55 \\
\hline$\gamma$-globulins (g/dl) & 29 & 1.62 & 0.98 & 3.57 & 0.53 \\
\hline AFP (IU/ml) & 30 & 36.41 & 1.30 & 350.00 & 89.07 \\
\hline HCV-RNA (IU/ml) & 28 & 519594.29 & 560.00 & 4420000.00 & 866.84 \\
\hline
\end{tabular}

$n$-number of patients with CHC; SD - standard deviation; $p$ - level of significance; BMI-body mass index; ${ }^{*}$ - histopathological scoring (see Material and methods),

$G$-total grade of liver necroinflammation; $S$-stage of fibrosis; AFP- $\alpha$-fetoprotein

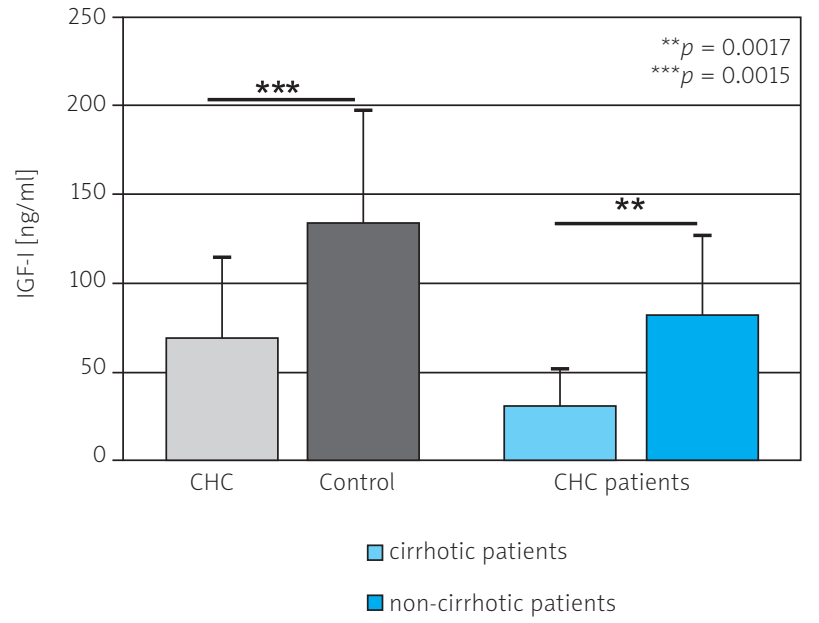

Fig. 1. Serum level of IGF-I in chronic hepatitis C (CHC) and control patients and comparison of serum level of IGF-I in cirrhotic and non-cirrhotic patients with $\mathrm{CHC}$

half a year [12]. This study demonstrated a statistically significant decrease in IGF-I level in patients with more advanced staging and liver steatosis, higher levels of AFP, gamma globulins and higher AST activity. Also a negative correlation was noted between IGF-I and insulin levels in patients with CHC. Additionally, we noted a statistically significant positive correlation between fasting insulin level and staging and gamma globulin level.

This study has confirmed the recently published data on nondiabetic HCV-infected patients, in whom negative cor-

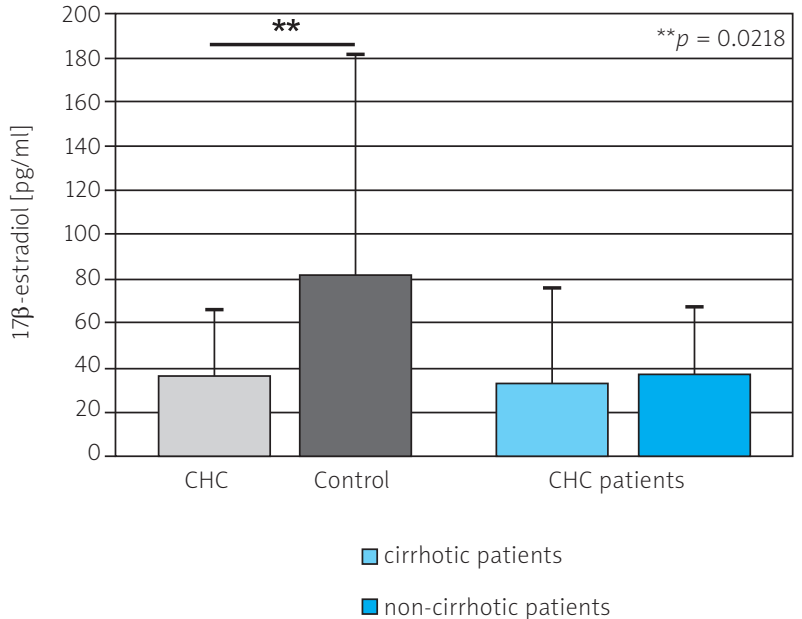

Fig. 2. Serum level of $17-\beta E$ in chronic hepatitis $C(C H C)$ and control patients and comparison of serum level of $17-\beta E$ in cirrhotic and non-cirrhotic patients with $\mathrm{CHC}$

relations were found between serum IGF-I concentration on one hand and fasting insulin and of HOMA-IR (homeostasis model assessment of insulin resistance) on the other [22]. The results suggested that IGF-I might be considered to represent an early marker of functional reserve or hepatocellular functional capacity [22]. Other authors linked the lowered hepatic production of IGF-I with gradual damage of hepatic parenchyma while the role of IGF-I system feedback was supposed to be more important in carcinogenesis linked to primary hepatocellular carcinoma, as compared to metasta- 


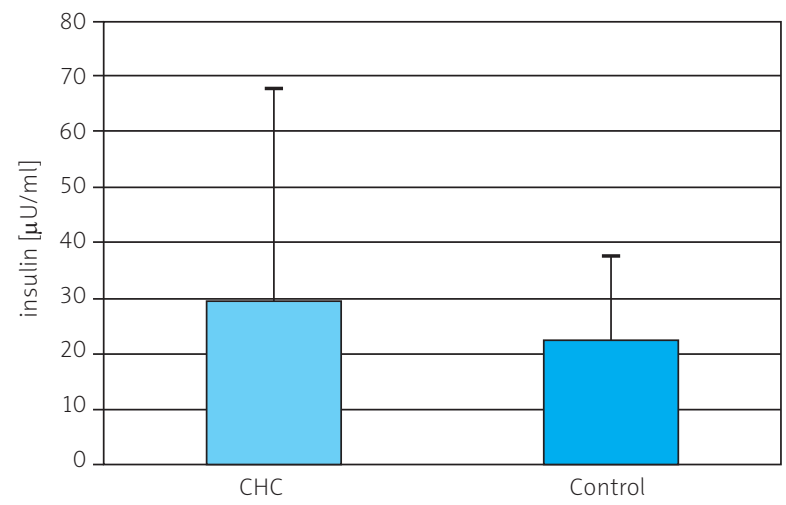

Fig. 3. Serum level of insulin in chronic hepatitis C (CHC) and control patients

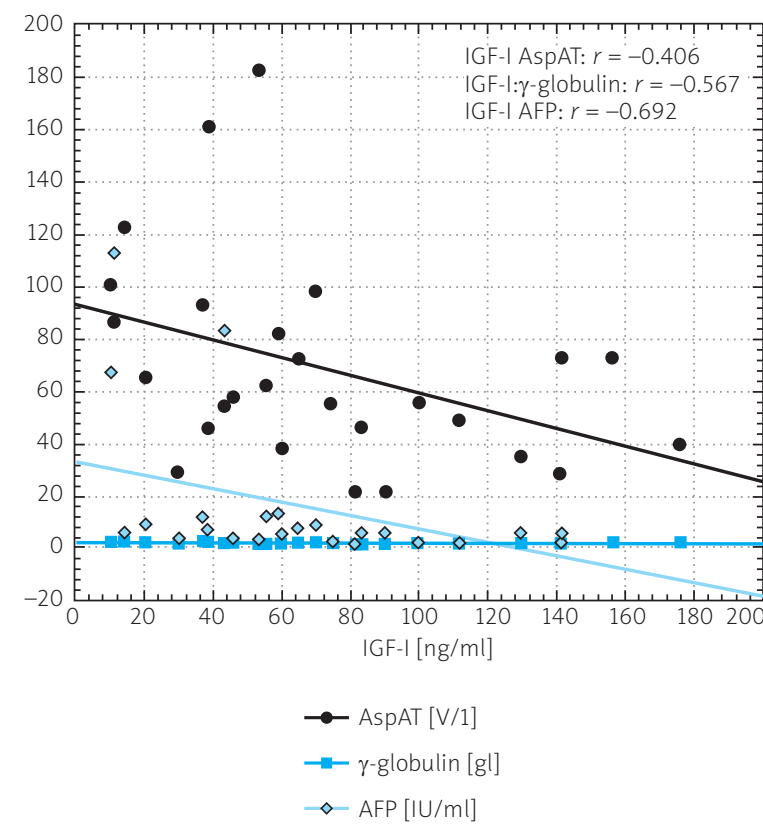

Fig. 5. Spearman's correlation between IGF-I serum level and for AST activity, $\gamma$-globulin and AFP serum levels in patients with chronic hepatitis $C$

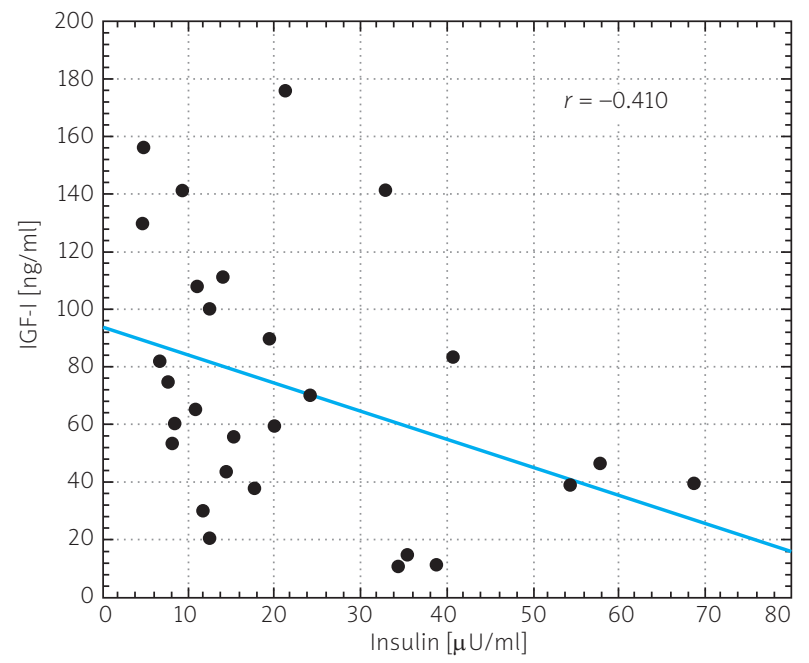

Fig. 7. Spearman's correlation between IGF-I serum level and for insulin level in patients with chronic hepatitis $C$

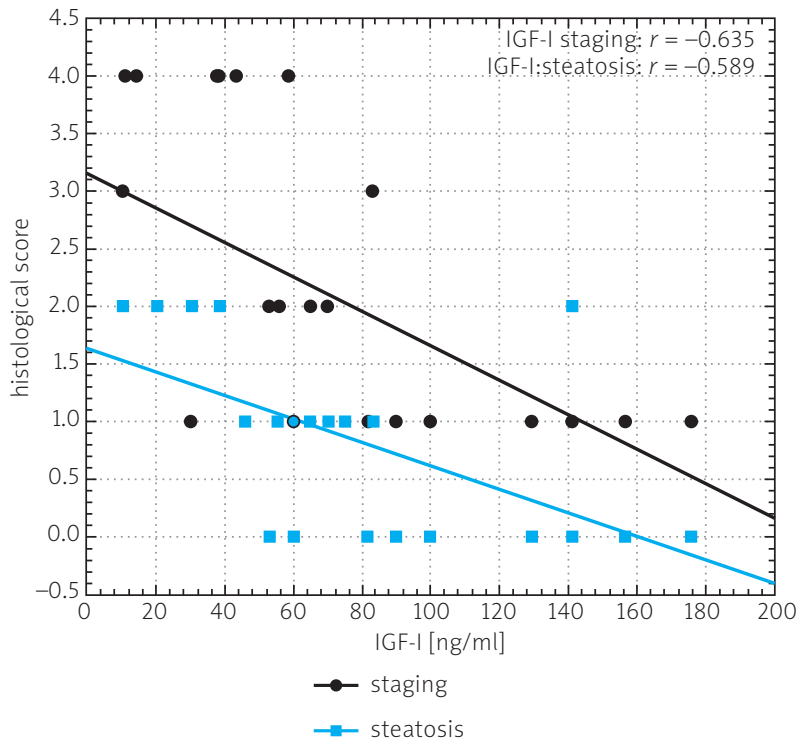

Fig. 4. Spearman's correlation between IGF-I serum level and for liver fibrosis (staging) and steatosis in patients with chronic hepatitis C

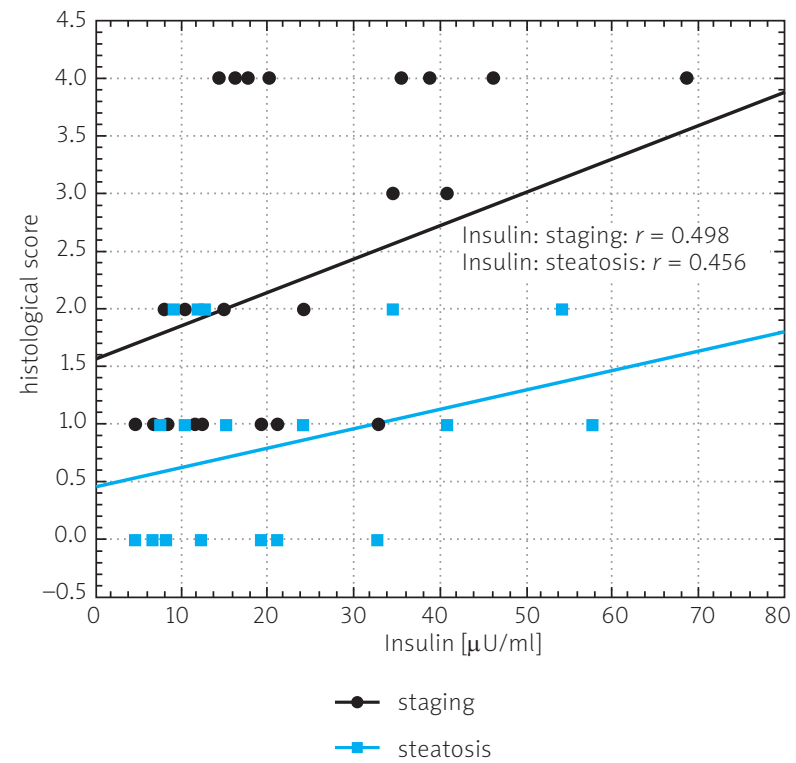

Fig. 6. Spearman's correlation between insulin serum level and for liver fibrosis (staging) and steatosis in patients with chronic hepatitis C

tic tumors in the liver [17]. Our current observations as well as our earlier study [23] have confirmed the negative correlation, described in the literature on the subject, between serum concentration of IGF-I on one hand and AST and ALT activities on the other [22].

The insulin serum level in our cirrhotic and non-cirrhotic patients was similar. Recent studies on insulin levels and insulin resistance associated with $\mathrm{HCC}$ in $\mathrm{CHC}$ reported by Hung et al. presented higher insulin levels in HCC patients than in those with chronic hepatitis and advanced fibrosis [24]. Serum insulin level, insulin resistance, type 2 diabetics and male sex were independently associated with HCC [24]. 
We did not detect any correlation between the insulin level and liver enzyme activities but, similarly to Mansour et al., we observed a positive correlation between insulin level and liver steatosis in CHC patients [25]. In our HCV-infected patients we noted a positive correlation between insulin level and age. In order to confirm the more frequent insulin resistance in these patients, in comparison with the noninfected patients, as described by other authors, an analysis of HOMA-IR values would be required $[22,26]$. Insulin resistance reflects the impaired synthesis of hepatic IGF-I, and low levels of IGF-I might play a role in the development of insulin resistance in HCV patients [22].

$17-\beta$ E suppresses progression of liver fibrosis and hepatocarcinogenesis. Estradiol suppressed hepatic fibrosis in a hepatic fibrosis model, inhibited activation of activator protein 1 and nuclear factor $\kappa B$ in cultured hepatocytes subjected to oxidative stress, and attenuated hepatic stellate cell activation in primary culture [19].

Our study revealed that the serum level of $17-\beta E$ in the $\mathrm{CHC}$ group negatively correlated with patients' age. We found that 17- $\beta \mathrm{E}$ level in the $\mathrm{CHC}$ group was lower than the level in control patients. This suggests that CHC patients carry a higher risk of liver injury and occurrence of HCC, also taking into account the lowered concentration of $17-\beta \mathrm{E}$. However, our results failed to confirm significant correlations between concentration of $17-\beta \mathrm{E}$ and parameters providing evidence for progression of $\mathrm{CHC}$ toward HCC, such as staging (advanced fibrosis) or AFP level. No correlations have been demonstrated between serum concentration of $17-\beta E$ and concentration of IGF-I.

Oral administration of exogenous estrogens exerts inhibitory route-dependent effects on all three components of the IGF-I ternary complex: IGFBP-3, ALS (acid-labile subunit) and IGF-I. These effects were independent of endogenous GH status [27]. Studies in vitro on Huh-7.5 cell lines demonstrated that administration of estradiol in the first days after infection of the cells with HCV inhibited production of HCV virions [28].

In conclusions: decreased IGF-I levels and increased levels of insulin characterize staging and liver steatosis in $\mathrm{CHC}$ patients better than estradiol serum levels. The lower serum level of $17-\beta \mathrm{E}$ in the $\mathrm{CHC}$ group than in control patients suggests that $\mathrm{CHC}$ patients carry a higher risk of liver injury and occurrence of HCC.

Source of support: a grant from the Minister of Education and Science, Warsaw, Poland (no. NN401009437).

\section{References}

1. Daughaday WH, Rotwein P. Insulin-like growth factors I and II. Peptide, messenger ribonucleic acid and gene structures, serum and tissue concentrations. Endocr Rev 1989; 10: 68-91.

2. Zarrilli R, Bruni CB, Riccio A. Multiple levels of control of insulin-like growth factor gene expression. Mol Cell Endocrinol 1994; 101: R1R14.

3. Alexia C, Fallot G, Lasfer M, Schweizer-Groyer G, Groyer A. An evaluation of the role of insulin-like growth factors (IGF) and of type IGF receptor signalling in hepatocarcinogenesis and in the resistance of hepatocellular cells against drug-induced apoptosis. Biochem Pharmacol 2004: 68: 1003-15.
4. Knittel T, Dinter C, Kobold D, Neubauer K, Mehde M, Eichhorst S, Ramadori G. Expression and regulation of cell adhesion molecules by hepatic stellate cells (HSC) of rat liver: involvement of HSC in recruitment of inflammatory cells during hepatic tissue repair. Am J Pathol 1999; 154: 153-67.

5. Samani AA, Yakar S, LeRoith D, Brodt P. The role of the IGF system in cancer growth and metastasis: overview and recent insights. Endocr Rev 2007; 28: 20-47.

6. Yakar S, Leroith D, Brodt P. The role of the growth hormone/insulinlike growth factor axis in tumor growth and progression: lessons from animal models. Cytokine Growth Factor Rev 2005; 16: 407-20.

7. Yakar S, Nunez NP, Pennisi P, et al. Increased tumor growth in mice with diet-induced obesity: impact of ovarian hormones. Endocrinology 2006 ; 147: 5826-43.

8. Wu A, Grant DB, Hambley J, Levi AJ. Reduced serum somatomedin activity in patients with chronic liver disease. Clin Sci Mol Med 1974; 47: 359-66.

9. Wu JC, Daughaday WH, Lee SD, Hsiao TS, Chou CK, Lin HD, Tsai YT, Chiang BN. Radioimmunoassay of serum IGF-I and IGF-II in patients with chronic liver diseases and hepatocellular carcinoma with or without hypoglycemia. J Lab Clin Med 1988; 112: 589-94.

10. Vyzantiadis T, Theodoridou S, Giouleme O, Harsoulis P, Evgenidis N Vyzantiadis A. Serum concentrations of insulin-like growth factor(IGF-I) in patients with liver cirrhosis. Hepatogastroenterology 2003; 50: 814-6.

11. Lorenzo-Zúñiga V, Bartolí R, Masnou H, Montoliu S, Morillas RM, Planas R. Serum concentration of insulin-like growth factor-I (IGF-I) as a marker of liver fibrosis in patients with chronic hepatitis C. Dig Dis Sci 2007; 52: 3245-50.

12. Wu YL, Ye J, Zhang S, Zhong J, Xi RP. Clinical significance of serum IGF-I, IGF-II and IGFBP-3 in liver cirrhosis. World J Gastroenterol 2004; 10: 2740-3.

13. Colakoğlu O, Taçkiran B, Colakoğlu G, Kizildaç S, Ari Ozcan F, Unsal B. Serum insulin like growth factor-1 (IGF-1) and insulin like growth factor binding protein-3 (IGFBP-3) levels in liver cirrhosis. Turk J Gastroenterol 2007; 18: 245-9.

14. Nikolić JA, Todorović V, Bozić M, Tosić L, Bulajić M, Alempijević T, Nedić O, Masnikosa R. Serum insulin-like growth factor (IGF)-II is more closely associated with liver disfunction than is IGF-I in patients with cirrhosis. Clin Chim Acta 2000; 294: 169-77.

15. Mazziotti G, Sorvillo F, Morisco F, et al. Serum insulin-like growth factor I evaluation as a useful tool for predicting the risk of developing hepatocellular carcinoma in patients with hepatitis C virusrelated cirrhosis: a prospective study. Cancer 2002; 95: 2539-45.

16. Okan A, Cömlekçi A, Akpinar H, Okan I, Yeçil S, Tankurt E, Simçek I. Serum concentration of insulin-like growth factor-I and insulin-like growth factor binding protein-3 in patients with chronic hepatitis. Scand J Gastroenterol 2000; 35: 1212-5.

17. Stuver SO, Kuper H, Tzonou A, Lagiou P, Spanos E, Hsieh CC, Mantzoros C, Trichopoulos D. Insulin-like growth factor 1 in hepatocellular carcinoma and metastatic liver cancer in men. Int J Cancer 2000; 87: $118-21$.

18. Su WW, Lee KT, Yeh YT, Soon MS, Wang CL, Yu ML, Wang SN. Association of circulating insulin-like growth factor 1 with hepatocellular carcinoma: one cross-sectional correlation study. J Clin Lab Anal 2010; 24: 195-200.

19. Shimizu I. Impact of oestrogens on progression of liver disease. Liver Int 2003; 23: 63-9.

20. Kasprzak A, Adamek A, Przybyszewska W, Olejniczak K, Biczysko W, Mozer-Lisewska I, Zabel M. p21/Waf1/Cip1 cellular expression in chronic long-lasting hepatitis C: correlation with HCV proteins (C, NS3, NS5A), other cell-cycle related proteins and selected clinical data. Folia Histochem Cytobiol 2009; 47: 385-94.

21. Pollak M. Insulin and insulin-like growth factor signalling in neoplasia. Nat Rev Cancer 2008; 8: 915-28.

22. Helaly GF, Hussein NG, Refai W, Ibrahim M. Relation of serum insulinlike growth factor-1 (IGF-1) levels with hepatitis C virus infection and insulin resistance. Transl Res 2011; 158: 155-62.

23. Kasprzak A, Adamek A, Przybyszewska W, et al. Expression of IGF and viral proteins (C, NS3, NS5A) in the livers of patients with chronic HCV infection. Adv Clin Exp Med 2011; 20: 263-73. 
24. Hung $\mathrm{CH}$, Wang JH, Hu TH, et al. Insulin resistance is associated with hepatocellular carcinoma in chronic hepatitis C infection. World J Gastroenterol 2010; 16: 2265-71.

25. Mansour HE, Farouk HM, Abdurrahman MA, Mostafa AA, Hassan IMA, Zarouk WA. Metabolic implications of hepatitis C virus infection and it's correlation to steatohepatitis in chronic hepatitis $C$ patients with and without type 2 diabetes. Infect Dis Res Treat 2010; 3: 25-33.

26. Lecube A, Hernández C, Genescà J, Simó R. Proinflammatory cytokines, insulin resistance, and insulin secretion in chronic hepatitis C patients: A case-control study. Diabetes Care 2006; 29: 1096-101.

27. Kam GY, Leung KC, Baxter RC, Ho KK. Estrogens exert route- and dose-dependent effects on insulin-like growth factor (IGF)-binding protein-3 and the acid-labile subunit of the IGF-ternary complex. J Clin Endocrinol Metab 2000; 85: 1918-22.

28. Hayashida K, Shoji I, Deng L, Jiang DP, Ide YH, Hotta H. 17ß-estradiol inhibits the production of infectious particles of hepatitis $C$ virus. Microbiol Immunol 2010; 54: 684-90.

\section{Address for correspondence}

\section{Agnieszka Adamek}

Department of Infectious Diseases

Poznan University of Medical Sciences

Szwajcarska 3

61-288 Poznań, Poland

e-mail: agnieszkaadamek@ump.edu.pl

Submitted: $\quad 31.05 .2011$

Accepted: $\quad 26.01 .2012$ 